\title{
Using Sensors Data and Emissions Information to Diagnose Engine’s Faults
}

\author{
Chunli XIE $^{1}$, Yuchao Wang ${ }^{1}$, John MacIntyre², Muhammad Sheikh², Mustafa Elkady ${ }^{3}$ \\ ${ }^{1}$ Traffic college, Northeast Forestry University, \\ No.26 Hexing road Xiangfang district, Harbin city, Heilongjiang province, 150040, China, \\ E-mail:XCL08@126.com \\ ${ }^{2}$ Faculty of Engineering and Advanced Manufacturing , University of Sunderland \\ Sunderland, SR6 ODD, UK \\ ${ }^{3}$ Department of Mechanical Engineering, School of Engineering, Lebanese International University \\ , Beirut, Lebanon \& Department of Automotive Engineering, Faculty of Engineering, Ain Shams \\ University, Cairo, Egypt
}

Received 17 September 2017

Accepted 18 May 2018

\begin{abstract}
This paper proposes using engine's sensors data flow and exhaust emissions information to diagnose engine's faults, enhancing the accuracy of fault diagnosis. Engine fault diagnosis model is built using both this information and the mature BP neural network and genetic algorithms. In order to verify the method, we build a test platform, which includes South Korea Hyundai fault test vehicle and X-431 diagnosis instrument and AUTO5-1 exhaust gas analyzer and computer. The diagnostic accuracy rate can reach $98.33 \%$, which is higher than using sensors data flow or the exhaust emissions information alone.

Keywords: Fault diagnosis; Neural network; Sensors data flow; Emissions information; Engine
\end{abstract}

\section{Introduction}

The engine is the main source of power and important component of the automobile an 2 , performance directly affects vehicle's safety and reliability. Due to their complex structure and heavy working conditions, the engine fault generally constitutes around $40 \%$ of the failures of the entire vehicle $^{1}$ Hence, it is of a great importance to developing new approaches for quick and accurate condition monitoring and fault diagnosis of the engines.
In the past few decades, research on the engine fault diagnosis (EFD) technology has become an active area in the field of vehicle engineering ${ }^{2-4}$. Kowalski ${ }^{5}$ presented the concept of a multi-dimensional marine engine diagnostic tool. The dimensions of the tool were diagnostic signals, which form a vector in affine space. The distance of the resulting vector from reference vectors for considered technical states of the engine was the result of the diagnosis. Moreover, diagnostic signals, derived from the composition of the exhaust gas, were also considered. Kowalski also chose the nitric oxide, carbon oxide, carbon dioxide and oxygen contents in the

* Corresponding author:Chunli XIE.E-mail:xc108@126.com 
exhaust gas and the temperatures behind all engine cylinders of the marine engine as diagnostic signals. $\mathrm{Wu}$ et al. $^{6}$ described an internal combustion engine fault diagnosis system using the manifold pressure of the intake system. To verify the effect of their proposed system for identification, both the radial basis function network (RBFN) and generalized regression neural network (GRNN) were used and compared in their study. The experimental results indicated the proposed system using manifold pressure signal as data input was effective for engine fault diagnosis in the experimental engine platform. In addition, Chen and Randall ${ }^{7}$ used two methods to diagnose misfire fault. The first method was based on the torsional vibration signals of the crankshaft, while the second method was based on the angular acceleration signals (rotational motion) of the engine block. Following the signal processing of the experimental and simulation signals, the best features were selected as the inputs of ANN networks. The ANN systems were trained using only the simulated data and tested using real experimental cases, indicating that the simulation model can be used for a wider range of faults for which it can be considered valid. The final results have shown that the diagnostic system based on simulation can efficiently diagnose misfire, including location and severity.

In general, currently available methods for engine fault diagnosis are mainly classified into model-based, knowledge-based and data-driven ${ }^{8,9}$ according to Prof. PM Frank from Germany who is an international fault diagnosis authority. ${ }^{28}$ Model-based diagnostics threshold are very accurate, but it is very timeconsuming and labour-demanding to identify the appropriate values of the model parameters. Thus, a model-based method is too expensive to comprehensively apply in practice. Moreover, due to the different natures of faults and the modelling uncertainty, no single model-based approach can diagnose all the faults. On the other hand, knowledge-based methods have the capability of handling the qualitative symptom descriptions ${ }^{9,10}$. Lastly, the data-driven methods were widely used for engine fault diagnosis. The main advantage of such methods is that they do not require much (or none at all) expertise of the operator/designer since they are mainly based on the data collected from the process, which can be historical (off-line) or realtime (on-line). This is a very important feature since data-driven methods can cope with the problem of data drift and other unpredicted disturbances. ${ }^{11}$

Based on these methods' merits and demerits, we propose in this paper using both sensors data flow and emissions information to diagnose the engine faults, which can give the comprehensive running information of engine and improve diagnostic accuracy. In this research, BP neural network and GABP tools are used to verify the method. Tests are done using Roll Brake Test Systems to realize fault diagnosis on-line during vehicle running at a different speed. In addition, the structure and work principle of the electronic control system is clearly presented. Engine fault diagnosis model is described. Experiments have been tested, which include the data sampling procedure and the application of the proposed model. The training process of the model and the results of diagnostic tests online are also analyzed.

The paper is organized as follows. Section 2 provides the research background, which includes electronic control system of the engine, BP neural network, Genetic Algorithms and GABP model. Section 3 presents the tests and experiments including experimental instruments and data acquisition. In Section 4, the algorithm model is trained using Matlab. Section 5 describes the test result of a simulation experiment. Finally, Section 6 presents the concluding remarks for this paper.

\section{Background}

\subsection{Electronic Control System of Engine}

The electronic control system of the engine is composed of sensors, actuators and engine control unit (ECU). The basic control loop is shown in Figure 1, which is Sensors detect the status and condition of the engine and send the parameters to the ECU. ECU is electronic control unit which controls a series of actuators of the internal combustion engine to ensure engine's optimal performance. It does this by reading values from a multitude of sensors within the engine bay, then interpreting the data using multidimensional performance maps (called lookup tables), and adjusting the engine actuators according to the information. Before ECUs, air-fuel mixture, ignition timing, and idle speed were mechanically set and dynamically controlled by mechanical and pneumatic means ${ }^{12}$. The components of sensors and actuators and basic function of ECU are shown in Figure2.

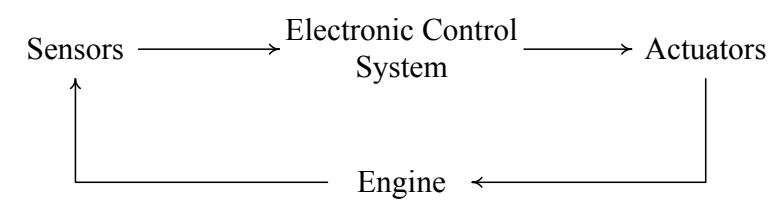

Fig. 1. The basic control loop of engine. 


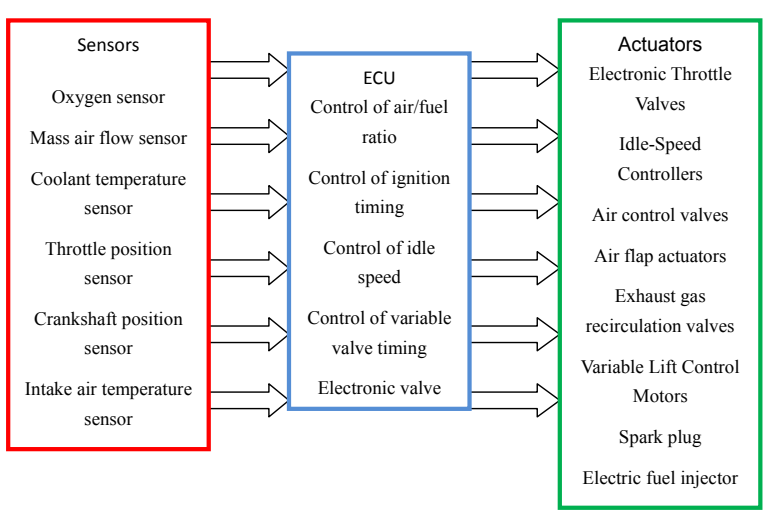

Fig. 2. Components of sensors and actuators and basic function of ECU.

\subsection{BP neural network}

Back propagation (BP) neural network algorithm is a multi-layer feed forward network trained based on an error back propagation algorithm and is one of the most widely applied neural network models. The BP network is used to learn and store a great deal of mapping relations of input-output model. In this network, there is no need to disclose in advance the mathematical equation that describes these mapping relations. Its learning rule is to adopt the steepest descent method in which the back propagation is used to regulate the weight value and threshold value of the network to achieve the minimum error sum of square ${ }^{13}$. The BP neural network toolbox in Matlab is chosen to get the ideal fault diagnosis results in this study. In order to obtain the best BP neural network structure, a large number of simulation experiments were conducted. Considering the mean squared error and percent error, hidden layer neurons of BP model are confirmed using minimum error and fast calculation speed, so hidden layer neurons are 17. Hidden and output layer incentive functions are purelin and tansig respectively to adjust weight values. The Figure 3 shows the two functions.
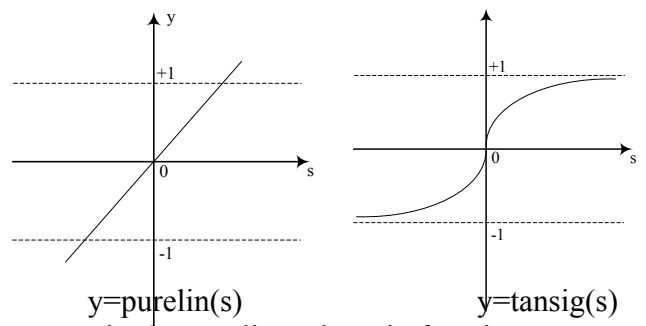

Fig. 3. Purelin and tansig function.

The input layer neurons represent input parameters of engine, while the output layer neurons represent faults, so nodes of input and output are confirmed. Table 1 lists the BP neural network model parameters.

Table 1. BP neural network model parameters.

\begin{tabular}{ccc}
\hline Item name & Content in detail & Parameters \\
\hline $\begin{array}{c}\text { Neurons node } \\
\text { number }\end{array}$ & Input layer & 10 \\
& Hidden Layer & 17 \\
& Output layer & 6 \\
Network structure & $\begin{array}{c}\text { Input-Hidden layer } \\
\text { function }\end{array}$ & Purelin \\
& Hidden-Output layer & Tansig \\
& transfer function & Trainlm \\
& Training function & 1000 \\
Training & Training times & 10 \\
parameters & Display Interval & 0.001 \\
& Training goal & 0.01 \\
\hline
\end{tabular}

\subsection{Genetic Algorithms $(G A)$}

Genetic Algorithms (GA) are probabilistic search algorithms that emulate the biological evolution of a population, by applying genetic operators that allow the recombination of the individuals, in order to strengthen their performance with regard to a quality function ${ }^{15}$. The selection of fitness function directly influences the convergence speed of genetic algorithm and whether it can find the optimal solution. Individual fitness (F) is calculated by Equation 1 .

$$
F_{i}=k \sum_{i=1}^{n}\left|y_{i}-O_{i}\right|
$$

Where $y_{i}$ is expectation output of node $i$, and $o_{i}$ is forecast output. $k$ is coefficient, which is a uniform random number rand between 0 and $1 . \mathrm{n}$ is an individual number.

\subsection{GABP model}

Although the BP algorithm is successful, it has some disadvantages. Because the BP neural network has adopted the gradient method, the problems include a slow learning convergent velocity and easy convergence to local minima, which cannot be avoided ${ }^{14}$. GA has been proven to effectively function with ANNs in determining the most compact architecture improving the estimation performance in a variety of problems ${ }^{16}$. This paper chose GA to optimize BP neural network to avoid BP algorithm convergence to local minima. The weights and thresholds of BP neural network are optimized using GA in training process, so called this 
algorithm is genetic algorithm BP neural network(GABP). First, we should confirm the original parameters of GA. The population size is set to 10 , and the evolution number is 50 times, crossover probability is 0.4 , mutation probability is 0.2 . Second, confirm fitness function using Equation 1.

In fitness proportionate individuals are selected with a probability that is directly proportional to their fitness values $^{26}$. Evaluate the probability, $P_{i}$ of selecting each individual in the population:

$$
P_{i}=F_{i} / \sum_{i=1}^{N} F_{i}
$$

Where $\mathrm{N}$ is population size.

Genetic operators are used to evolving the next generation of individuals from the current population ${ }^{26}$. Here we choose crossover and mutation. So, next step is crossover and mutation using the equation 3 and $4{ }^{17}$. According to the probability $P i$, randomly select two antibodies $a$ and $a_{1}$ from the population, then the crossover operation of two antibodies in j-bit can be described as follows:

$$
\begin{aligned}
& a_{k j}=a_{k j}(1-b)+a_{l j} b \\
& a_{l j}=a_{l j}(1-b)+a_{k j} b
\end{aligned}
$$

Where $b$ is a variable randomly distributed from 0 to 1 . For the selected antibody $a_{i}$, the mutation of j-gene can be calculated as follows:

$$
a_{i j}= \begin{cases}a_{i j}+\left(a_{i j}-a_{\max }\right) * f(g) & r>0.5 \\ a_{i j}+\left(a_{\min }-a_{i j}\right) * f(g) & r \leq 0.5\end{cases}
$$

Where $a_{\max }$ and $a_{\min }$ are the low and upper bounds of the gene value respectively. $r$ is a variable randomly distributed from 0 to 1 . Mutation probability is basically a measure of the likeness that random elements of your chromosome will be flipped into something else. For example, if your chromosome is encoded as a binary string of length 100 if you have 1\% mutation probability it means that 1 out of your 100 bits (on average) picked at random will be flipped. So $f(g)$ is the mutation probability defined as follows:

$$
f(g)=r_{2}\left(1-g / G_{\max }\right)^{2}
$$

Where $\mathrm{g}$ is the current iterative number, $\mathrm{G}_{\max }$ is the maximal iterative number, $r_{2}$ is a variable randomly distributed from 0 to 1 .

\section{Tests and Experiments}

The detection of faults in their early stages is beneficial for the avoidance of larger and more severe faults. Fault detection and diagnosis (FDD) methods are used to monitor the system and identify faults occurring and type and location. If a fault is correctly detected and diagnosed, corrective measures can be applied to repair the fault and reduce any further damage to the system. Many researchers carried out intensive research on FDD $^{18-21}$. Authors ${ }^{22}$ used the energy balance equations which balance the relation among pressure, mass flow rate and power at various locations to diagnose the faults of the space shuttle main engine. Authors ${ }^{23}$ used vibration signals to diagnose the faults of diesel internal combustion engine's valve trains. Meanwhile, changes of exhaust emissions content reflect engine performance $^{24}$. Exhaust emissions compositions of engine mainly include $\mathrm{HC}, \mathrm{NOx}, \mathrm{CO}, \mathrm{CO} 2, \mathrm{O} 2$, water vapour etc. They must change in some range due to the change of operating status at different conditions, various mechanical and electronic faults ${ }^{25}$. So exhaust emissions can reflect engine faults. On the other hand, engine's sensors data can also reflect engine's condition and faults. In order to get the comprehensive information of engine to help us diagnose the faults accurately, sensors data ${ }^{27}$ and emissions information are all used to diagnose the faults of the engine, which are shown in Table2. Table 2 presents data about the engine,

\begin{tabular}{|c|c|c|c|}
\hline $\begin{array}{l}\text { Input } \\
\text { item }\end{array}$ & Feature factors(unit) & $\begin{array}{l}\text { Output } \\
\text { item }\end{array}$ & Faults type \\
\hline $\mathrm{x}_{1}$ & $\mathrm{CO}\left(10^{-2} \mathrm{cc}\right)$ & $\mathrm{y}_{1}$ & No fault \\
\hline $\mathrm{x}_{2}$ & $\mathrm{CO}_{2}\left(10^{-2} \mathrm{cc}\right)$ & $\mathrm{y}_{2}$ & $\begin{array}{l}\text { fuel injector } \\
\text { fault }\end{array}$ \\
\hline $\mathrm{x}_{3}$ & $\mathrm{O}_{2}\left(10^{-2} \mathrm{cc}\right)$ & $\mathrm{y}_{3}$ & $\begin{array}{l}\text { Ignition coil } \\
\text { fault }\end{array}$ \\
\hline $\mathrm{x}_{4}$ & $\mathrm{HC}\left(10^{-6} \mathrm{cc}\right)$ & $\mathrm{y}_{4}$ & $\begin{array}{c}\text { Throttle } \\
\text { position } \\
\text { sensor fault }\end{array}$ \\
\hline $\mathrm{x}_{5}$ & $\mathrm{NO}_{\mathrm{x}}\left(10^{-6} \mathrm{cc}\right)$ & $\mathrm{y}_{5}$ & $\begin{array}{c}\text { air flow } \\
\text { sensor fault }\end{array}$ \\
\hline $\mathrm{x}_{6}$ & $\begin{array}{l}\text { Crankshaft rolling } \\
\text { speed }(r / \mathrm{min})\end{array}$ & $\mathrm{y}_{6}$ & $\begin{array}{c}\text { Oxygen } \\
\text { sensor fault }\end{array}$ \\
\hline $\mathrm{x}_{7}$ & $\begin{array}{c}\text { Throttle } \\
\text { position }(m v)\end{array}$ & & \\
\hline $\mathrm{x}_{8}$ & air flow sensor $(\mathrm{Hz})$ & & \\
\hline $\mathrm{x}_{9}$ & Oxygen sensor $(m v)$ & & \\
\hline $\mathrm{x}_{10}$ & $\begin{array}{l}\text { Intake air } \\
\text { temperature } \\
\text { sensor }\left({ }^{\circ} \mathrm{C}\right)\end{array}$ & & \\
\hline
\end{tabular}
which are called faults feature factors as inputs of the BP neural network and faults type, which are the output of the BP neural network.

Table 2. Faults feature factors and faults type. 


\subsection{Experimental instruments}

A test platform is built to verify the proposed method. The platform includes South Korea Hyundai fault test vehicle, X-431 diagnosis instrument and AUTO5-1 exhaust gas analyzer as well as a computer. Figure 4 shows the diagnosis test vehicle, which has eight faults setting control modules. Their names are engine(ECU) faults, ABS(antilock brake system) faults, TCS(Traction Control System), FATC(Full Automatic Air Conditioning), TCU(Transmission Control Unit), ECS(Engine Control System), ETACS(Electronic Time Alarm Control System), Air bag. In this paper, the focus will only be on the engine faults setting module because it has a more direct connection with emissions and system can get the sensors data easily. The engine can be inserted into different sensors faults and actuators faults, then diagnose the inserted faults using the proposed method and get the diagnosis results. Comparing diagnosis results with the inserted faults, which can test the diagnostic system.

The X-431 diagnosis instrument is shown in Figure 5, which can get sensors data flow. Figure 6 shows the AUTO5-1 exhausts gas analyzer, which can get exhaust information of engine. The vehicle only runs at the idle condition, because we need to connect the experiment instruments with the vehicle and get the information. In order to simulate real road conditions, we use Burke Porter's 3600 roll brake test system. Figure 7 shows the vehicle running on the platform. We can get the vehicle's information on different speed and diagnose the faults real-time (on-line).

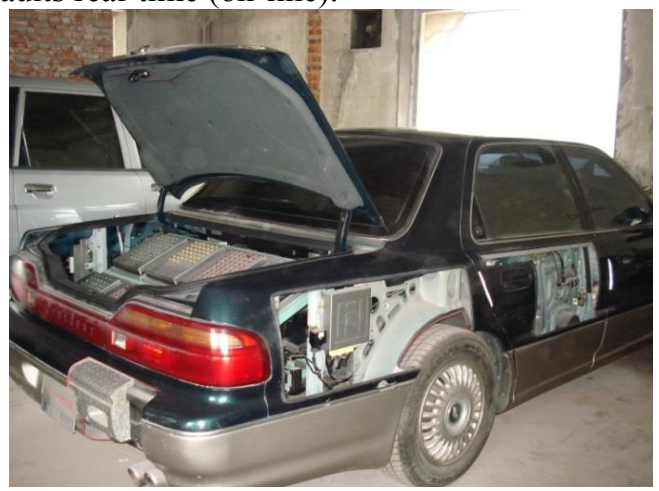

Fig. 4. Diagnosis test vehicle.

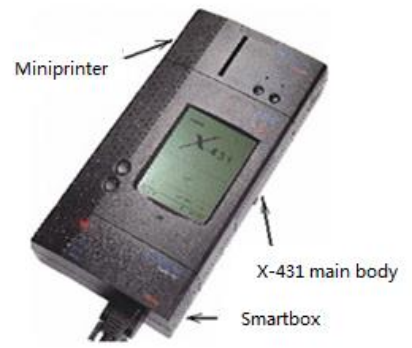

Fig. 5. The main body appearance of X-431.

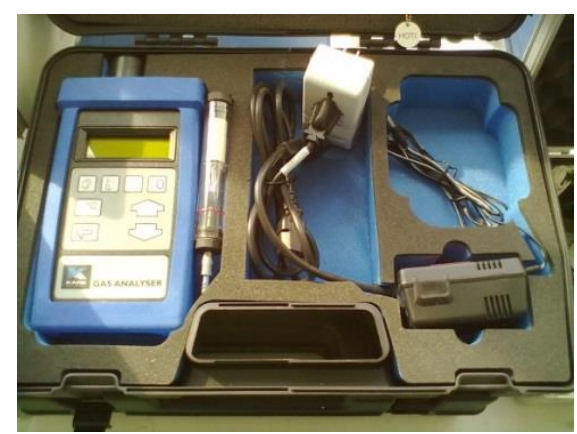

Fig. 6. AUTO5-1 exhausts gas analyzer.

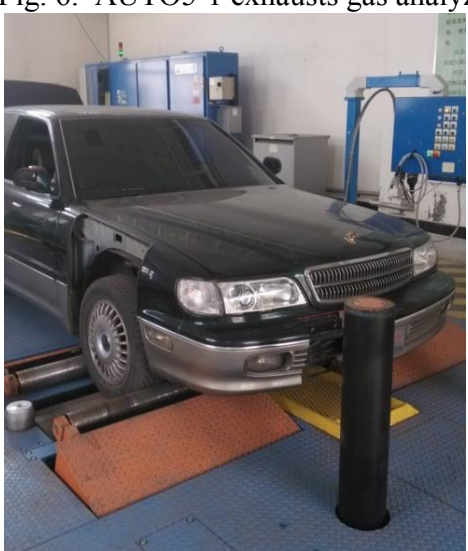

Fig. 7. Vehicle running on the 3600 roll brake test systems.

\subsection{Experiment data acquisition}

It should be noted that the use of artificial neural networks requires the collection of large amounts of data sets. They require obtaining more than one hundred sets of data for each operating condition, which are used to teach the network. We use the diagnostic port MITSUBISHI/HYUNDAI-12+16. The 16 frame port is standard RS232. Sensors data flow can be got using X431 PCLINK data communication soft, which can realize the following functions shown in table3. Figure 8 represents the software main interface.

Table 3. PCLINk data communication soft functions.

\begin{tabular}{ll}
\hline Functions & Explanation \\
\hline Monitor and alarm monitor the engine and give the alarm if \\
the engine has abnormal. \\
diagnose the faults of the engine. \\
$\begin{array}{l}\text { Diagnose } \\
\text { Restore and check restore and check data of engine such as } \\
\text { speed, coolant temperature and so on. } \\
\text { reset system such as deleting fault code, } \\
\text { recovering system etc. }\end{array}$ \\
\hline
\end{tabular}

The test vehicle and all the instruments can work normally before doing experiments in order to get the right information about the engine. Faults' code must be cleared on the X-431 diagnostic instrument and the AUTO5-1 exhaust gas analyzer must be reset. All of the fault set modules of test vehicle must keep normal. We must keep the X-431 and the AUTO5-1 to work 
together, which can ensure we get the information on same time. Firstly, the vehicle runs at idle speed, and then it keeps running at this condition and gets the normal data. Parts of normal and different faults data engine at idle speed are shown in Table 4. Secondly, vehicle will accelerate until $1800 \mathrm{r} / \mathrm{min}$, and then the vehicle keeps running at this speed and gets the normal data. Parts of normal data and different faults data engine at $1800 \mathrm{r} / \mathrm{min}$ are shown in table 5 . We performed these steps 20 times and got 120 groups data.

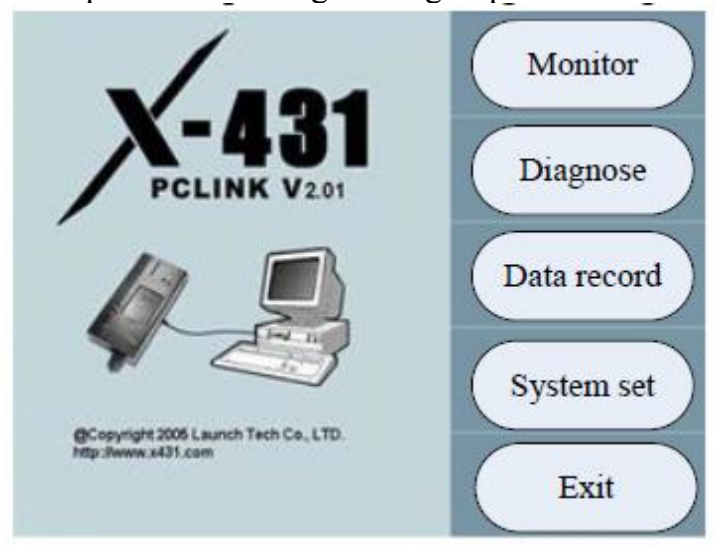

Fig. 8. Main interface of PCLINK diagnosis software.

Table 4. Training data engine at idle speed.

\begin{tabular}{|c|c|c|c|c|c|}
\hline Fault type & $\mathrm{x}_{1}$ & $\mathrm{x}_{2}$ & $\mathrm{x}_{3}$ & $\mathrm{x}_{4}$ & $\mathrm{x}_{5}$ \\
\hline $\mathrm{y}_{1}$ & 0.01 & 9.1 & 4.43 & 1 & 431 \\
\hline $\mathrm{y}_{1}$ & 0.01 & 12.7 & 3.38 & 1 & 664 \\
\hline $\mathrm{y}_{2}$ & 0.07 & 7.8 & 10.82 & 1532 & 91 \\
\hline $\mathrm{y}_{2}$ & 0.08 & 7.8 & 10.81 & 1534 & 95 \\
\hline $\mathrm{y}_{3}$ & 0.01 & 10 & 9.32 & 1 & 984 \\
\hline $\mathrm{y}_{3}$ & 0.02 & 9.3 & 9.7 & 1 & 1008 \\
\hline $\mathrm{y}_{4}$ & 0.17 & 8.9 & 8.7 & 1344 & 38 \\
\hline $\mathrm{y}_{4}$ & 0.16 & 9.2 & 8.57 & 1344 & 44 \\
\hline $\mathrm{y}_{5}$ & 0.11 & 10.3 & 4.98 & 1543 & 89 \\
\hline $\mathrm{y}_{5}$ & 0.12 & 10.4 & 4.93 & 1543 & 92 \\
\hline $\mathrm{y}_{6}$ & 0.06 & 8.7 & 8.76 & 883 & 30 \\
\hline $\mathrm{y}_{6}$ & 0.07 & 9.1 & 8.52 & 915 & 31 \\
\hline Fault type & $\mathrm{x}_{6}$ & $\mathrm{x}_{7}$ & $\mathrm{x}_{8}$ & $\mathrm{x}_{9}$ & $\mathrm{x}_{10}$ \\
\hline $\mathrm{y}_{1}$ & $\begin{array}{c}718 . \\
8\end{array}$ & 507.8 & 23.1 & 39.1 & 17 \\
\hline $\mathrm{y}_{1}$ & $\begin{array}{c}687 . \\
5\end{array}$ & 507.8 & 23.1 & 39.1 & 17 \\
\hline $\mathrm{y}_{2}$ & $\begin{array}{c}718 . \\
8\end{array}$ & 507.8 & 31.2 & 58.6 & 16 \\
\hline $\mathrm{y}_{2}$ & $\begin{array}{c}687 . \\
5\end{array}$ & 507.8 & 31.2 & 58.6 & 16 \\
\hline $\mathrm{y}_{3}$ & $\begin{array}{c}718 . \\
8\end{array}$ & 507.8 & 43.8 & 39.1 & 17 \\
\hline $\mathrm{y}_{3}$ & $\begin{array}{c}687 . \\
5\end{array}$ & 507.8 & 43.8 & 39.1 & 17 \\
\hline
\end{tabular}

Table 4, continued:

\begin{tabular}{|c|c|c|c|c|}
\hline $\mathrm{y}_{4}$ & $\begin{array}{c}718 . \\
8\end{array}$ & 19.5 & 37.5 & 58.6 \\
\hline $\mathrm{y}_{4}$ & $\begin{array}{c}687 . \\
5\end{array}$ & 19.5 & 31.2 & 58.6 \\
\hline $\mathrm{y}_{5}$ & $\begin{array}{c}718 . \\
8\end{array}$ & 507.8 & 0 & 273.4 \\
\hline $\mathrm{y}_{5}$ & $\begin{array}{c}687 . \\
5\end{array}$ & 507.8 & 0 & 293 \\
\hline $\mathrm{y}_{6}$ & $\begin{array}{c}718 . \\
8\end{array}$ & 507.8 & 37.5 & 19.5 \\
\hline $\mathrm{y}_{6}$ & $\begin{array}{c}687 . \\
5\end{array}$ & 507.8 & 37.5 & 19.5 \\
\hline
\end{tabular}

Note: $x 1-\mathrm{CO}, x 2-\mathrm{CO} 2 x 3-\mathrm{O} 2, x 4-\mathrm{HC}, x 5$ - NOx $x 6$ - engine speed, $x 7$ - position of throttle valve, $x 8$ - air flow rate, $x 9$ oxygen sensor, $x 10$ - air temperature sensor;

$y 1$-normal, $y 2$ - nozzle fault, $y 3$-ignition coil fault, $y 4$ - throttle valve sensor fault, $y 5$ - air flow sensor fault, $y 6$-oxygen sensor fault

Table 5. Training data of engine accelerate to $1800 \mathrm{r} / \mathrm{min}$

\begin{tabular}{cccccc}
\hline Fault type & $\mathrm{x}_{1}$ & $\mathrm{x}_{2}$ & $\mathrm{x}_{3}$ & $\mathrm{x}_{4}$ & $\mathrm{x}_{5}$ \\
\hline $\mathrm{y}_{1}$ & 0 & 13.5 & 2.99 & 46 & 1397 \\
$\mathrm{y}_{1}$ & 0 & 13.5 & 2.93 & 47 & 1590 \\
$\mathrm{y}_{2}$ & 0 & 11.6 & 3.78 & 1 & 1115 \\
$\mathrm{y}_{2}$ & 0 & 11.2 & 3.52 & 1 & 1487 \\
$\mathrm{y}_{3}$ & 0.04 & 9.3 & 8.63 & 1 & 1228 \\
$\mathrm{y}_{3}$ & 0.06 & 9.4 & 8.59 & 1 & 1215 \\
$\mathrm{y}_{4}$ & 0.01 & 13.8 & 2.28 & 1 & 1412 \\
$\mathrm{y}_{4}$ & 0.01 & 13.8 & 2.52 & 1 & 1027 \\
$\mathrm{y}_{5}$ & 0.79 & 14.9 & 0.41 & 322 & 143 \\
$\mathrm{y}_{5}$ & 0.84 & 14.9 & 0.4 & 356 & 133 \\
$\mathrm{y}_{6}$ & 0.01 & 13.9 & 2.39 & 1 & 1675 \\
$\mathrm{y}_{6}$ & 0.01 & 13.5 & 2.58 & 1 & 1916 \\
\hline Fault type & $\mathrm{x}_{6}$ & $\mathrm{x}_{7}$ & $\mathrm{x}_{8}$ & $\mathrm{x}_{9}$ & $\mathrm{x}_{10}$ \\
\hline $\mathrm{y}_{1}$ & 1875 & 957 & 156.2 & 58.6 & 54 \\
$\mathrm{y}_{1}$ & 1812.5 & 937.4 & 150 & 58.6 & 54 \\
$\mathrm{y}_{2}$ & 1875 & 1074.2 & 187.5 & 39.1 & 32 \\
$\mathrm{y}_{2}$ & 1812.5 & 1054.6 & 181.2 & 39.1 & 32 \\
$\mathrm{y}_{3}$ & 1875 & 2382.7 & 368.8 & 39.1 & 0 \\
$\mathrm{y}_{3}$ & 1812.5 & 2382.7 & 406.2 & 39.1 & 0 \\
$\mathrm{y}_{4}$ & 1718.8 & 39.1 & 150 & 39.1 & 0 \\
$\mathrm{y}_{4}$ & 1812.5 & 39.1 & 156.2 & 58.6 & 0 \\
$\mathrm{y}_{5}$ & 1875 & 917.9 & 0 & 917.9 & 54 \\
$\mathrm{y}_{5}$ & 1812.5 & 937.4 & 0 & 937.4 & 54 \\
$\mathrm{y}_{6}$ & 1781.2 & 937.4 & 156.2 & 39.1 & 32 \\
$\mathrm{y}_{6}$ & 1718.8 & 839.8 & 156.2 & 19.5 & 32 \\
\hline & & & & &
\end{tabular}

\section{Algorithm model training}

\subsection{BP Neural network training}

BP neural network model is built using Matlab software and trained using the data. Figure 9 shows the training interface, which gives the structure of the neural network, algorithms parameters, calculates progress and 
training plots. Figure 10 presents change curve of BP neural network training mean squared error with training epochs. From Figure 10(a) we can see the best validation performance is $1.49 \times 10^{-5}$ at epoch 13 , which mean the neural network convergence speed is very fast. Figure11 shows the BP neural network training objective gradient curve, while Figure 12 shows the linear correlation-regression curve of a relative output of the BP neural network. The training curves of the engine are provided using different data at the idle speed and accelerate to $1800 \mathrm{r} / \mathrm{min}$ respectively.

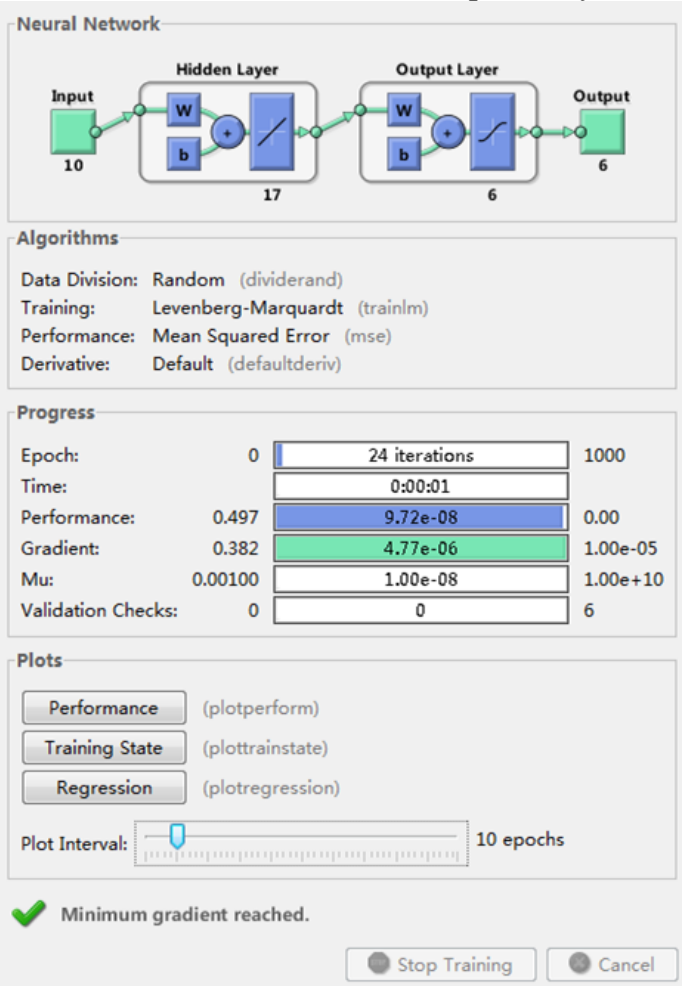

Fig. 9. Neural network training interface.

Figure 11 shows that neural network model is trained to 24 epochs by iteration, and the declining gradient can reach required minimum. Target error is in the minimum range, which can illustrate that training of neural network model is ideal. It can meet convergence requirement. It can reach the minimum gradient $1 \mathrm{e}-005$ and the minimum target error less than 0.001, which illustrate that the model can change and confirm the weights that link different layers. Figure 11(a) shows that best validation performance is $5.7463 \mathrm{e}-005$ at epoch 24 .

\subsection{GABP training}

The best individual fitness curve and best fitness were obtained by training (showing in Figure 12). The steps of convergence GABP neural network model is shown in Figure13.

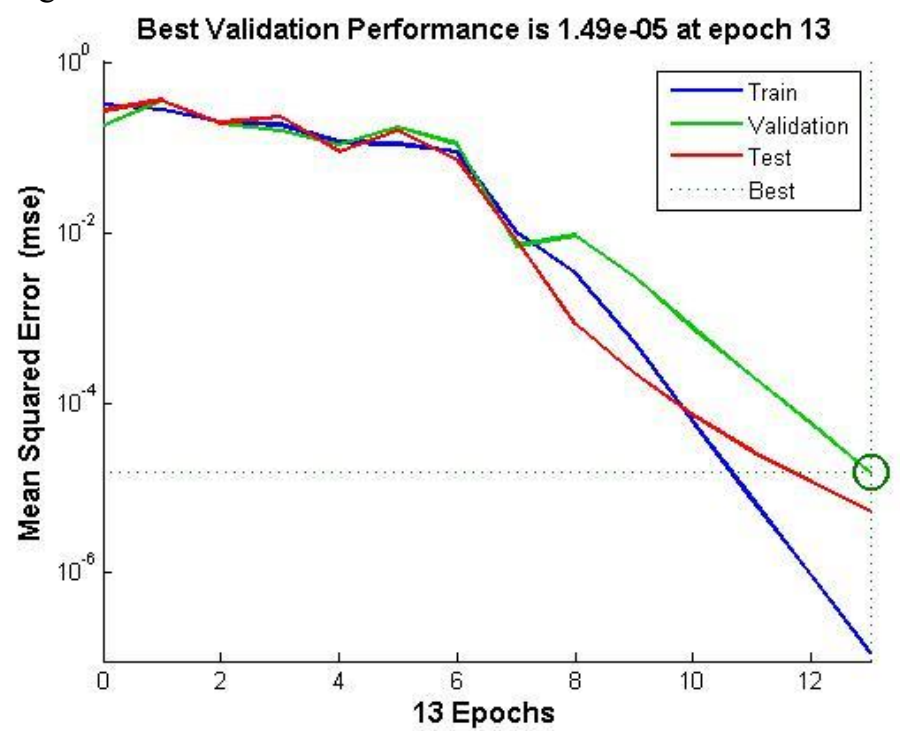

(a)Engine at idle speed

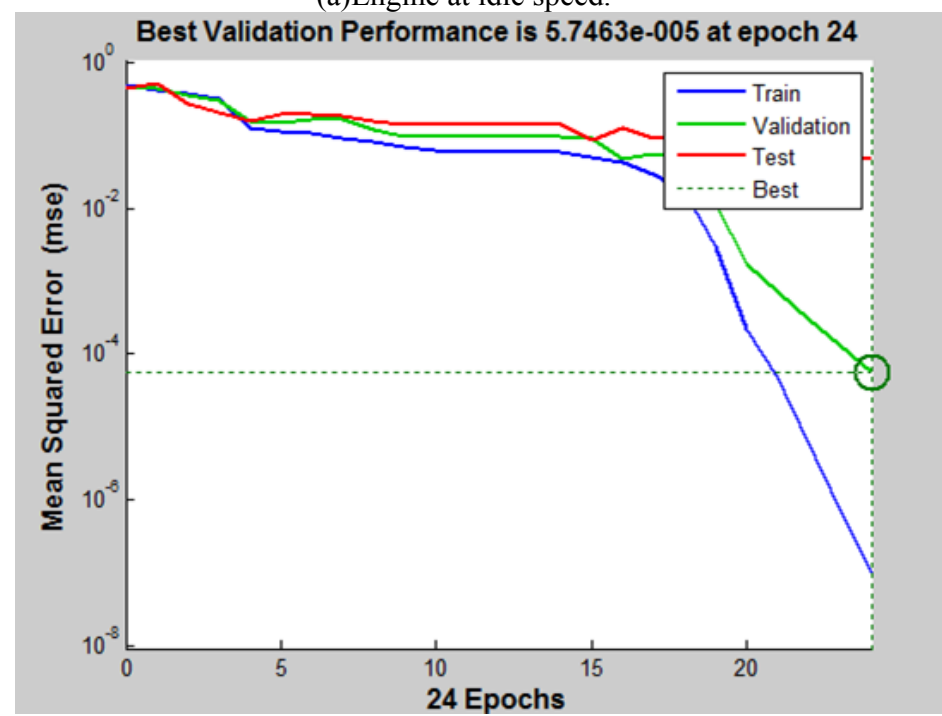

(b)Engine at accelerating to $1800 \mathrm{r} / \mathrm{min}$.

Fig. 10. The change curve of BP neural network training mean squared error with the training epoch. 


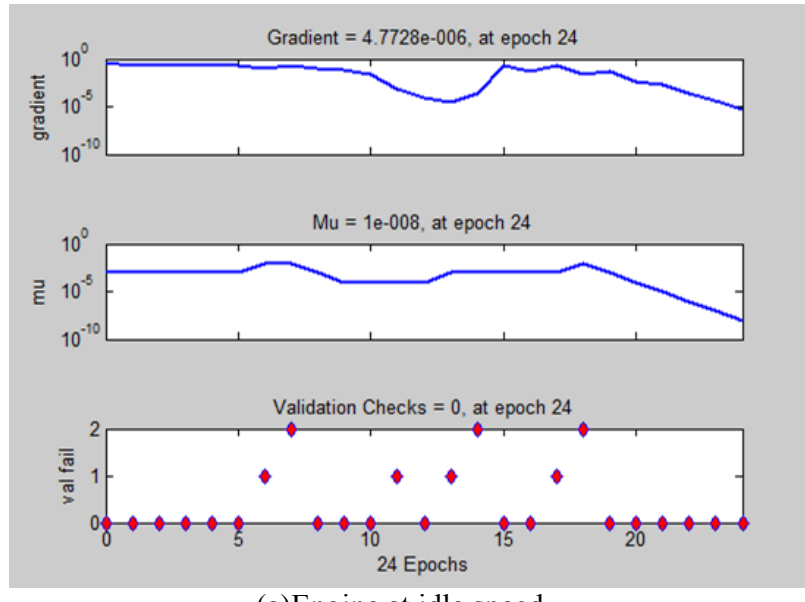

(a)Engine at idle speed.
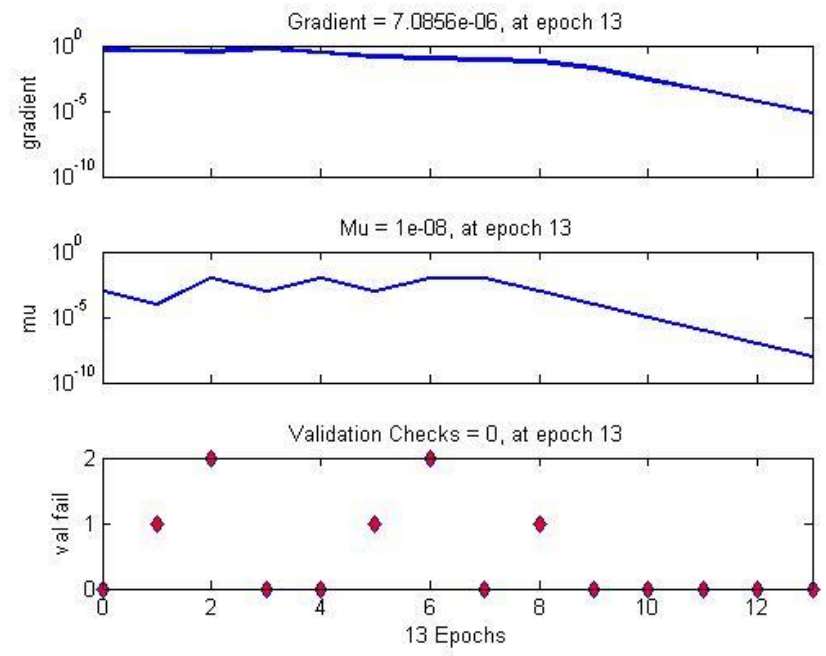

(b)Engine at accelerating to $1800 \mathrm{r} / \mathrm{min}$.

Fig. 11. BP neural network training objective gradient curve.

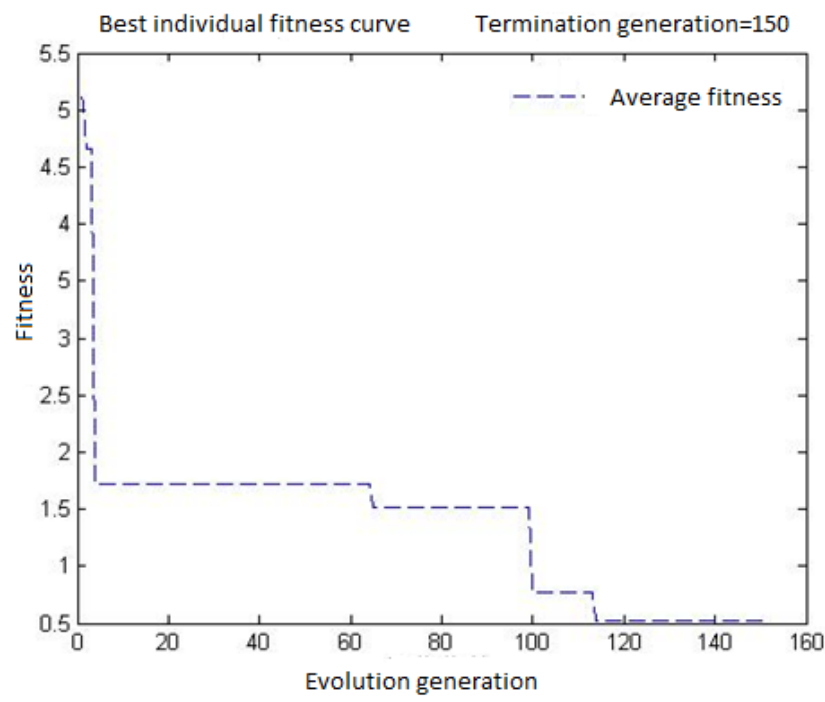

Fig. 12. Best individual fitness curve.

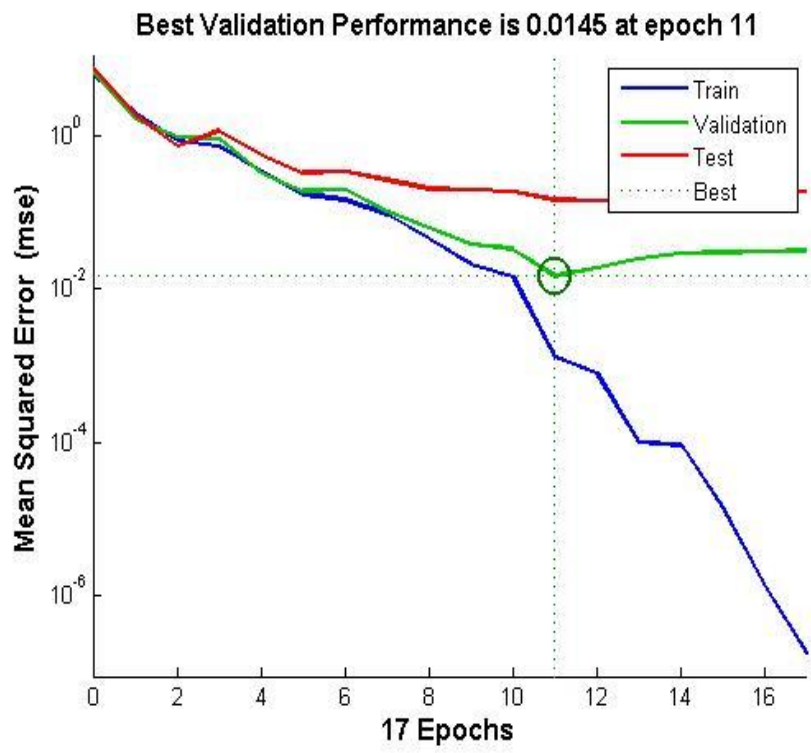

Fig. 13. Process of GABP network training.

As it can be seen from Figure 12, the best individual fitness curve stabilizes after 110 generations, which indicates that the best individual has been achieved optimizing network to 110 generations. Comparing the same structure pure BP neural network, the GABP can improve the performance of the neural network, but it also increases the training convergence time.

\subsection{Test on line}

We test faults diagnosis on line using the model, which has been trained BP neural network. Table 6 provides a group of data engine accelerate to $1800 \mathrm{r} / \mathrm{min}$. The data have been normalized. The normalized calculated method is shown as follows:

Within a given bounded data set there is often a large difference between the maximum and the minimum values. When normalization is applied to a data set its' upper and lower bounds are scaled to appreciably smaller magnitudes. We use the basic z-score normalization that is obtained by using Equation 6

$$
\mathrm{x}^{\prime}=\frac{x-\mu(x)}{\sigma(x)}
$$

Where $\mu(\mathrm{x})$ and $\sigma(\mathrm{x})$ denote the normal data and the standard deviation of $x$, respectively. This normalization produces a data set, where each point has a normal close to zero and a variance close to one.

Figure 14 provides the parameters curve when the Oxygen sensor fault is set. Table 7 provides diagnosis 
results of test data. It can be seen that the real output of the neural network is close to the expected output.

Table 6. A group of test data.

\begin{tabular}{cccccc}
\hline & $x_{1}$ & $x_{2}$ & $x_{3}$ & $x_{4}$ & $x_{5}$ \\
\hline 1 & 0.0000 & 0.0045 & 0.0012 & 0.0201 & 0.9452 \\
2 & 0.0000 & 0.0038 & 0.0020 & 0.0000 & 0.7373 \\
3 & 0.0001 & 0.0034 & 0.0028 & 0.0003 & 0.3983 \\
4 & 0.0000 & 0.0048 & 0.0012 & 0.0003 & 0.4038 \\
5 & 0.0007 & 0.0050 & 0.0001 & 0.3175 & 0.0180 \\
6 & 0.0000 & 0.0045 & 0.0012 & 0.0003 & 1.0000 \\
\hline & $x_{6}$ & $x_{7}$ & $x_{8}$ & $x_{9}$ & $x_{10}$ \\
\hline 1 & 0.6282 & 0.3182 & 0.0520 & 0.0203 & 0.0187 \\
2 & 0.6282 & 0.3520 & 0.0650 & 0.0136 & 0.1109 \\
3 & 0.6282 & 0.8860 & 0.1538 & 0.0136 & 0.0000 \\
4 & 0.6282 & 0.0136 & 0.0520 & 0.0203 & 0.0000 \\
5 & 0.6282 & 0.3317 & 0.0000 & 0.3114 & 0.0187 \\
6 & 0.6282 & 0.3182 & 0.0520 & 0.0068 & 0.1109 \\
\hline
\end{tabular}

Table 7. Diagnosis results.

\begin{tabular}{ccccccccc}
\hline Sample & \multicolumn{9}{c}{ BP neural network real output } & & $\begin{array}{c}\text { Expected } \\
\text { output }\end{array}$ \\
\hline 1 & $\mathbf{0 . 9 8 8 6}$ & 0.1143 & 0.0707 & 0.0090 & 0.0903 & 0.0607 & $(100000)$ \\
2 & 0.0986 & $\mathbf{0 . 9 7 9 0}$ & 0.0789 & 0.0924 & 0.1022 & 0.0968 & $(010000)$ \\
3 & 0.1018 & 0.1015 & $\mathbf{0 . 9 4 0 8}$ & 0.1027 & 0.1428 & 0.1118 & $(001000)$ \\
4 & 0.1193 & 0.0996 & 0.1175 & $\mathbf{0 . 9 4 7 1}$ & 0.0732 & 0.0854 & $(000100)$ \\
5 & 0.0617 & 0.0862 & 0.1401 & 0.0810 & $\mathbf{0 . 9 1 8 1}$ & 0.0838 & $(000010)$ \\
6 & 0.0444 & 0.1025 & 0.0132 & 0.0429 & 0.0001 & $\mathbf{0 . 9 3 2 7}$ & $(000001)$ \\
\hline
\end{tabular}

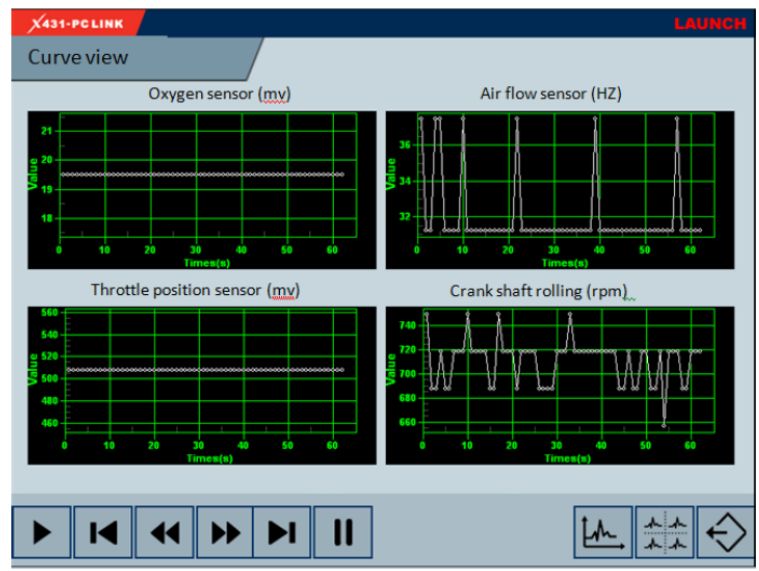

Fig. 14. Parameters curves when oxygen sensor has a fault.

\section{Discussions}

We used X-431 to get the test vehicle's sensors data and used the AUTO5-1 exhaust gas analyzer to get the emissions information. These data were sent to BP neural network and GABP model to train the two models then using the trained model to diagnose faults.
We test 120 groups of data, which can be diagnosed are 118 groups of data. The accuracy of diagnosis can reach $98.33 \%$. If only use sensors data flow and exhaust emissions information the accuracy of diagnosis is 93.33 and $83.33 \%$ respectively. It means that we use sensors data flow and exhaust emissions information to diagnose engine's faults is valid and better than only use one.

We also diagnosed these data using GABP model, it can diagnose all faults accurately and the precision is higher than BP neural network, but training convergence time is increased.

It is must be pointed that $\Omega$ annot guarantee the exhaust emission information $p$ up with the sensor data flow because they are collected using different equipment. X-431 gets the engine sensors data and-then sends the data to the computer. AUTO5-1 exhaust gas analyzer gets the exhaust gas information and then sends the information to the computer. There is no connection between the two devices. They send information independently, so we cannot insure that they can get the engine's information at the same time. How can we get synchronous data is needed to research deeply. The model should be modified further for raising the accuracy of fault diagnosis on the other hand.

\section{Acknowledgement}

This work is supported by the Fundamental Research Funds for the Central Universities (NO.2572018BG02).

\section{References}

1. Y.S. Wang, Q.H. Ma and Q. Zhu etc. An intelligent approach for engine fault diagnosis based on HilbertHuang transform and support vector machine. Applied Acoustics. 75 (2014) 1-9.

2. Ashkan Moosavian, G. Najafi and Barat Ghobadian. Piston scuffing fault and its identification in an IC engine by vibration analysis. Applied Acoustics. 102 (2016) 40-48.

3. Xin-jun Wang, Yan-ping Cai and Xu-ze Lin. Diesel Engine PT Pump Fault Diagnosis based on the Characteristics of its Fuel Pressure. IERI Procedia. 7 (2014) 84-89. 
4. Sofiane Ahmed Ali, Mohammed Guermouche and Nicolas Langlois. Fault-tolerant control based Super-Twisting algorithm for the diesel engine air path subject to loss-of-effectiveness and additive actuator faults. Applied Mathematical Modelling. 39 (2015) 4309-4329.

5. Jerzy Kowalski. Concept of the multidimensional diagnostic tool based on exhaust gas composition for marine engines. Applied Energy. 150 (2015) 18.

6. Jian-Da $\mathrm{Wu}$, Cheng-Kai Huang and Yo-Wei Chang etc. Fault diagnosis for internal combustion engines using intake manifold pressure and artificial neural network. Expert Systems with Applications. 37 (2010) 949-958.

7. Jian Chen and Robert Bond Randall. Improved automated diagnosis of misfire in internal combustion engines based on simulation models. Mechanical Systems and Signal Processing. 64-65 (2015) 58-83.

8. Pak KinWong, JianhuaZhong and ZhixinYang etc. Sparse Bayesian extreme learning committee machine for engine simultaneous fault diagnosis. Neurocomputing. 174 (2016) 331-343.

9. Chi Man Vonga, Pak Kin Wong and Ka In Wong. Simultaneous-fault detection based on qualitative symptom descriptions for automotive engine diagnosis. Applied Soft Computing. 22 (2014) 238-248.

10. Jian Chen and Robert Bond Randall. Intelligent diagnosis of bearing knock faults in internalcombustion engines using vibration simulation. Mechanism and Machine Theor. 104 (2016) 161-176.

11. Radu-Emil Precup, Plamen Angelov and Bruno Sielly etc. An overview on fault diagnosis and nature-inspired optimal control of industrial process applications. Computers in Industry. 23 (2015) 1-20.

12. Wikipedia. Online Referencing, https://en.wikipedia.org/wiki/Engine_control_unit( 2011, accessed 4 April 2017)

13. Jing Li, Ji-hang Cheng and Jing-yuan Shi etc. Brief Introduction of Back Propagation(BP) Neural Network Algorithm and Its Improvement. Advances in Computer Science and Information Engineering. 169 (2012) 553-558.

14. SUN Yan-jing, ZHANG Shen and MIAO Changxin etc. Improved BP Neural Network for Transformer Fault Diagnosis. Journal of China
University of Mining \& Technology. 17(1) (2007) 0138-0142.

15. Mariela Cerrada, Grover Zurita, Diego Cabrera, René-Vinicio Sánchez etc. Fault diagnosis in spur gears based on genetic algorithm and random forest. Mechanical Systems and Signal Processing. 70-71 (2016) 87-103

16. Muhammet Unal, Mustafa Onat and Mustafa Demetgul etc. Fault diagnosis of rolling bearings using a genetic algorithm optimized neural network Measurement. 58 (2014) 187-196.

17. Fafa Chen, Baoping Tang and Renxiang Chen. A novel fault diagnosis model for gearbox based on wavelet support vector machine with immune genetic algorithm. Measurement. 46 (2013) 220 232.

18. Ashkan Moosavian, Meghdad Khazaee and Gholamhassan Najafi etc. Spark plug fault recognition based on sensor fusion and classifier combination using Dempster-Shafer evidence theory. Applied Acoustics. 93 (2015) 120-129.

19. Weiliang Wu, Tian Ran Lin and Andy C.C. Tan. Normalization and source separation of acoustic emission signals for condition monitoring and fault detection of multi-cylinder diesel engines. Mechanical Systems and Signal Processing. 64-65 (2015) 479-497.

20. Yuefei Wang, Chuang Xue and Xiaohan Jia. Fault diagnosis of reciprocating compressor valve with the method integrating acoustic emission signal and simulated valve motion. Mechanical Systems and Signal Processing. 56-57 (2015) 197-212.

21. Tao Qiu, Xuchu Li and Yan Lei etc.The prediction of fuel injection quality using a NOx sensor for the onboard diagnosis of heavy-duty diesel engines with SCR systems. Fuel. 141 (2015) 192-199.

22. JihyoungCha,ChulsuHa,SanghoKo and JayeKoo. Application of fault factor method to fault detection and diagnosis for space shuttle main engine. Acta Astronautica. 126 (2015) 517-527.

23. Justin Flett and Gary M. Bone. Fault detection and diagnosis of diesel engine valve trains. Mechanical Systems and Signal Processing. 72-73 (2016) 316327.

24. Weifeng Li, Zhongchang Liu and Zhongshu Wang. Experimental and theoretical analysis of effects of $\mathrm{N} 2, \mathrm{O} 2$ and $\mathrm{Ar}$ in excess air on combustion and NOx emissions of a turbocharged NG engine. Energy Conversion and Management. 97 (2015) $253-264$. 
25. Jun Ye..Application of extension theory in misfire fault diagnosis of gasoline engines. Expert Systems with Applications. 36 (2009) 1217-1221.

26. Lariza Laura de Oliveira, Alex A. Freitas, Renato Tinós. Multi-objective genetic algorithms in the study of the genetic code's adaptability. Information Sciences. 425 (2018) 48-61
27. Javadi, S. H., Detection over sensor networks: a tutorial. IEEE Aerospace and Electronic Systems Magazine .31 (2016) 2-18

28. PM. Frank. Fault diagnosis in dynamic systems using analytical and knowledge-based redundancyasurvey and some new results. Automatica. 26 (1990) 459-474 